University for Business and Technology in Kosovo

UBT Knowledge Center

UBT International Conference

2015 UBT International Conference

Nov 7th, 9:00 AM - 5:00 PM

\title{
Marketing of a tourism destination - Case study Rugova
}

Luljeta Shaqiri

University for Business and Technology, luljeta.shaqiri@yahoo.com

Ilia Kristo

University for Business and Technology, ilia.kristo@yahoo.com

Ylber Limani

University for Business and Technology, ylber.limani@ubt-uni.net

Follow this and additional works at: https://knowledgecenter.ubt-uni.net/conference

Part of the Business Commons

\section{Recommended Citation}

Shaqiri, Luljeta; Kristo, Ilia; and Limani, Ylber, "Marketing of a tourism destination - Case study Rugova" (2015). UBT International Conference. 38.

https://knowledgecenter.ubt-uni.net/conference/2015/all-events/38

This Event is brought to you for free and open access by the Publication and Journals at UBT Knowledge Center. It has been accepted for inclusion in UBT International Conference by an authorized administrator of UBT Knowledge Center. For more information, please contact knowledge.center@ubt-uni.net. 


\title{
Marketing of a tourism destination - Case study Rugova
}

\author{
${\text { Luljeta Shaqiri }{ }^{1} \text {, Ilia Kristo }}^{1}$, Ylber Limani ${ }^{1}$ \\ ${ }^{1}$ University for Business and Techology, Management Business and Economics, \\ Pristina, Kosovo \\ \{luljeta.shaqiri, ilia.kristo\}@yahoo.com, ylber.limani@ubt-uni.net
}

\begin{abstract}
Tourism is one of the most complex activities of a modern society. In developed countries but also in some of transition countries, tourism is important product and employing generator. Even in Kosovo, tourism is an essential economic branch, whereby marketing has very significant impact for its functioning. Therefore, in this paper are addressed marketing concepts by focusing on those of tourism as a development indicator of the country. To achieve visitors satisfaction in touristic destination Rugova, we have implemented analyze with the citizens that have visited Rugova.
\end{abstract}

Keywords: Marketing, Tourism

\section{Introduction}

Regarding the marketing as an economic tool in itself, undoubtedly that it has a very significant impact on the functioning of the economy of the Republic of Kosovo, as well as by raising the possibilities of tourism in foreign markets. At the same time the marketing might also play an important role in the other sectors of the economy such as agriculture, tourism, agribusiness etc.

Concerning the development of tourism, Kosovo has some great natural potentials, due to the excellent geographical position with the breakdown of endless and wonderful landscapes with mountains, beautiful lakes and sources. In this research, we have found that tourism is a very sensitive sector, whereas, its planning and development should be done with a great moderation and dedication. Even though, the tourism has a variety of economic impacts, directly and indirectly. Therefore, the tourists contribute to sales, profits, employment, tax revenues, etc.. On the one hand, from our qualitative and quantitative research, it is concluded that the direct effects surely occur within the major companies, hotels, restaurants, tourist agencies, retail trade, etc. One the other hand, though, the indirect effects may include the supplying of businesses with all necessary goods and services related to tourism. This means that, through indirect effects, the industry of tourism affects the other sectors of the economy as well. In conclusion we say that tourism is one of the major economic activities and tools onto managing the economic development of Kosovo.

We have organized this research within three main phases:

- The first phase deals with the general research of the current state of tourism in some countries of the world, and the same time we compare these data to the Kosovo and the region.

- The second stage implies explorative research in this field, where with the interviews conducted with tourists we try build clearer views of this sector through their direct perceptions.

- The third phase involves analysis, discussion and presentation of results.

\section{The Marketing of tourist destination}

\subsection{Identifying of a tourist destination}

A definition of the tourist destination says: "The destination is a geographical area that includes a critical part of development in order to satisfy the objectives of the travelers". The tourist destinations are communities located within certain geographical positions which attract 
tourists with attractions and their features based on motivations that push tourists to travel. Therefore, the identification of a destination resort includes: the identification, analysis and determination of all sizes, attractions, tourist sites or resources that are capable of generating tourist flows.

So, it is a product composed of many elements, such as accommodation, restaurants, bars etc.. Then, there are natural attractions such as mountains, forests, beaches, as well as other sorts of attractions created by people's hands including: parks, museums, galleries etc. Thus, the costs to the private sector used to increase investment in improving the quality of tourism product as an offer, the promotion of tourist company, the training of the staff in order to improve the quality of services etc. While, the public sector spending are provided for the improvement and creation of tourist infrastructure, by improving of the quality of product for different categories of tourists in the region, by improving the ways of promotion in our country, by providing increased public services and further development of human resources as well.

\subsection{The Region of Rugova as a tourist site}

It is a mountainous territory in the range of Alp Mountains, which coincides with the Basin of Peja River lying between the Haya Mountains, Shtedim, Lumbardh and Kopranik. The region of Rugova with $200 \mathrm{~km}^{2}$ constitutes the third region in the Bjeshkët e Nemuna ('Damned Mountains'), located in the western part of Kosovo, in the north-west of the territory of Peja. However, the natural conditions with the terrain, the altitude, the climate, the water, the soil composition, the forests etc., those are the characteristics which make this one of the most specific tourist zone in itself, based on the geographical and ethnographic area as a whole. It is worth mentioning that the Rugova Mountains have been part of Albanian culture for a long time. Its natural beauty with high ecological and geo-morphological values, with its very rich flora and fauna, with the extraordinary landscape of localities, rivers and lakes, which represent some of the most attractive natural beauties even in Europe, together with the large number the cultural and historical monuments it is consisted of, this makes it as one of the places with a very big priority in the region for near future.

\subsection{The mix elements of the marketing in tourism}

The mix marketing elements of tourism include all the controllable variables that combine or complement each other in order to achieve the maximization of profit through satisfying consumer wants and needs in this case. The mix elements of the marketing in tourism are:

\subsubsection{The Product}

The main criteria for assessing the integrity are determined by considering the needs and requirements of all major categories of tourist customers. The tourist product, like any other product has a timeframe or a cycle, its beginning, its growing climate, the maturity and declining periods as well. 


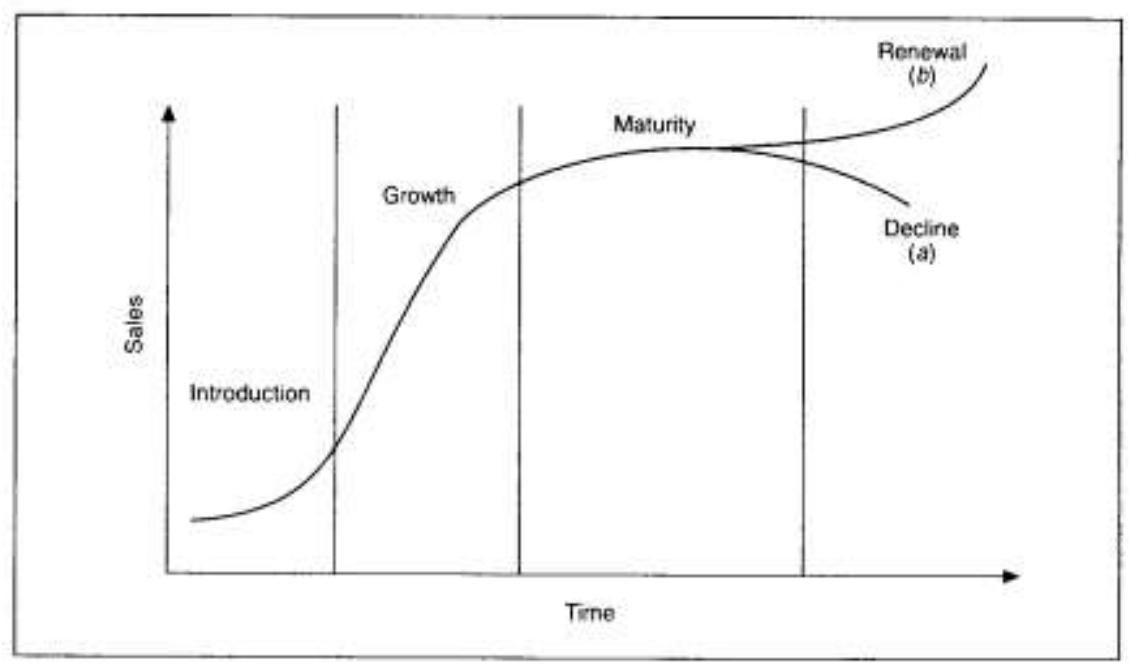

Figure 1: Butler's model: Life cycle of the tourism product

Based on Butler's model, the products of tourism throughout their life cycles and passes go through six

stages:

The first phase is the entrance or exploration of the market. Then, the second phase is the inclusion or the attempts to increase the number of tourists. The next phase is the development which encouraged foreign investors, whereas, the fourth stage is the maturity of the tourism product. The fifth phase consists of stagnation where the maximal capacities are met, while the sixth stage is divided into two sub stages, including the depression phase, where the tourists prefer other destinations or the second one which is time of rebuilding capacities, where we attempt to create a new product.

\subsubsection{The Price}

The price is a very important element in the mix marketing because it brings benefits to the organization. For certain reasons and features of the markets on tourism make the pricing process more complex.

In this regard, there are defined three pricing methods:

The method oriented on costs;

The demand-driven method; and

The method oriented on competition;

\subsubsection{The Distribution}

The distribution channels in tourism make possible the arrangement and delivery of the tourism product from " manufacturer 'to the final customer.

The distribution of tourism product is realized through:

The direct channels from the manufacturer to the consumer and

Through the indirect channels of the marketing intermediaries

\subsubsection{The Promotion}

Organizations that deal with marketing of tourist destinations make their publicity through brochures, $\mathrm{TV}$, personal selling, sales promotion, participation in fairs and exhibitions etc. 


\section{The Tourist Market}

\subsection{The characteristics of the tourist market}

The market of tourism is an expression often used to show that the combination of economic activities and operators competing to produce and share a "product', which could be a package of goods and tourist services.

The market of tourism can be studied in these following directions:

According to the purpose of the travelling,

According to the age structure of participants in the tourist movement,

By the type of tourist movement,

According to the nature of travel, the means of transport used, the distance of movement, etc.

\subsection{The tourist consumer behavior}

The objective of the analysis on customers consists on the introducing of a model that explains the determination of prices and the exchanged quantities of consumer goods. The consumer behavior in the market tourist resort is synthesized in such a way as to explain and predict their choices as circumstances change "environment" within which he is forced to choose. Rather, the solution of the problem of the customer's choice will depend on the demand for every element of the product or of the amount requested, as a function of all of the elements that make up the prices of the required package and disposable incomes coming from it.

\section{The Opportunity and Methodology}

To make a scan of the current state of tourism in Rugova region, we initially explored the tourist offer that Rugova Resorts bring, such as natural and cultural resources, tourist services offered, the economic, socio-demographic etc.

Besides the tourist offer, to be a genuine research, first we analyzed the tourist demand, what the visitors want to see next time in Rugova, what did they like them and what are their requirements so far. However, in order to realize the best tourist supply and demand, we have made search marketing for primary data collection from visitors in this case.

The type of research has been mainly descriptive, since we needed specific descriptive data. The instrument used to obtain these data were structured questionnaires to tourists. The structure of the questionnaire is closed questions and with defined alternatives and open-ended questions, where they can describe their ideas, explain the reasons for visiting etc.

\subsection{The Output A}

Based on the results of marketing research, the Rugova Resorts was mainly visited by groups of young people from 25 to 35 years, then the next age group of 35 to 45 years and a smaller percentage are tourists age was the group of 45 to 55 years. 


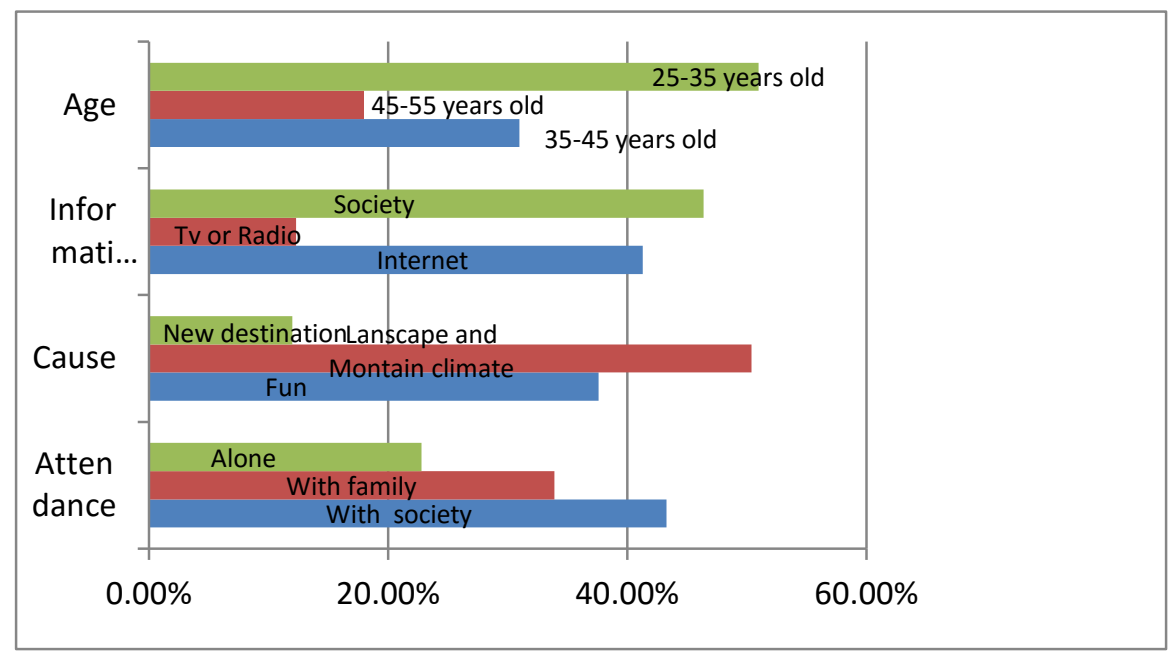

Figure 2: The results from the (potential) client survey

Concerning the information about the beautiful locations, the visitors get them primarily from their friends and the Internet as well, but also from the TV or radio are very important informants for tourists. The landscape and climate are the main factors that push people to visit Rugova, but fun and exploration for a new destination for tourists are other causes in Rugova as well. Visits and excursions in Rugova mountains are mainly accompaniments or visits of tourist groups usually composed by youngsters with their mates, then families and tourists who choose to relax with these natural beauties.

\subsection{The Output B}

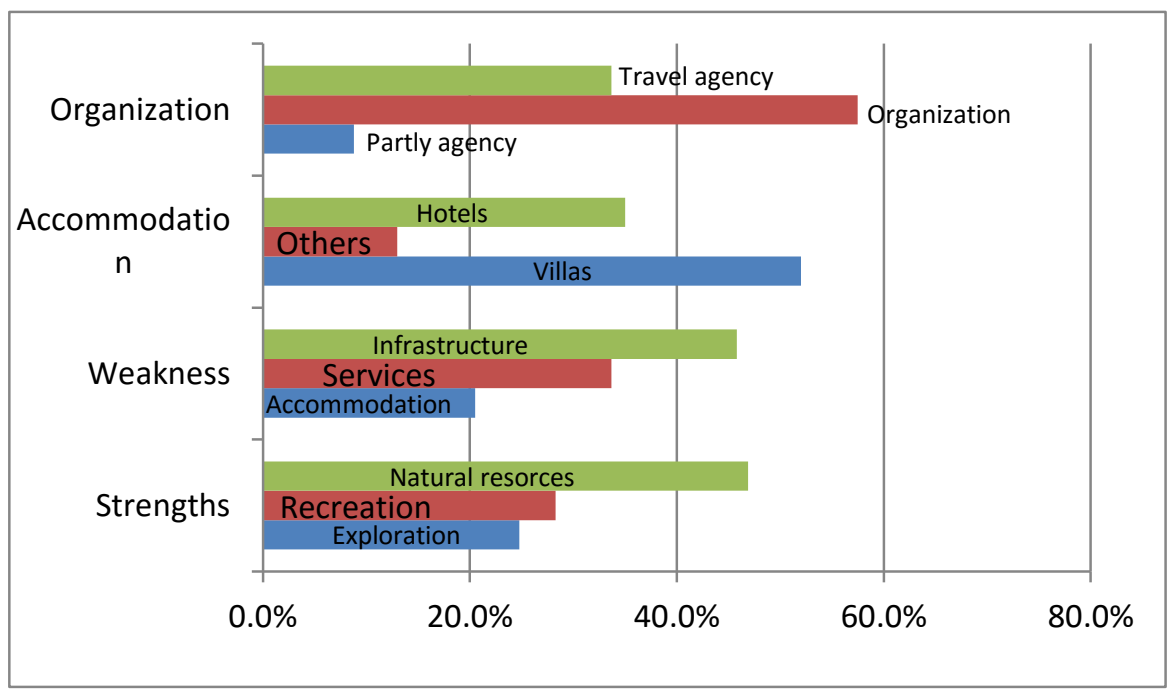

Figure 3: The results from the situation survey

The trips are usually organized by citizens themselves, but there are frequent trips organized by tourist agencies, tourist groups, so there is no difficulty for these kind of resort assortments to Rugova.

The visitor accommodation often consists of villas and hotels. According to our survey, visitors are mostly satisfied with relaxing time in Rugova, and their assessment about these attractive places are 
in satisfying level so far, except the needs and requests on improving the infrastructure, services and accommodations.

The top advantages of these resorts in Rugova are considered its natural attractions, entertainments and outdoor explorations.

\section{Conclusions and recommendations}

The Region of Rugova has many natural and cultural assets which are not yet being used for tourism. The Region Rugova with its potential of multiple natural beauties and its rich natural resources of water, with its lakes at different altitudes, numerous caves, and picturesque landscapes of mountain ranges associated with each other with their mountains peaks, with its rich flora and fauna covering the entire region which offers great opportunities for tourism.

From the information we have received from tourism operators, there is a modest increase on the number of tourists compared to last year, but this sort of tourism is mainly compound by young people and families who come from our country, there are not too many foreign visitors, so far.

Therefore, the tourism should be supported more by the level of government with adequate policies and a clear vision which enables this sector to move towards a positive direction.

Based on the achieved results, we believe that Rugova Region as a tourist product is in its second phase of development, namely the inclusion / growth, where the number of tourists comes increasing smoothly, but it should be endowed with clear normative instruments in favor of passing towards the stage of development of tourism as a product, to encourage foreign investors and begin to provide additional services for tourists at the same time.

Some of the recommendations to develop the marketing of tourism destinations are:

1. The necessary investments in road infrastructure, in order to ease the traveling for visitors.

2. Increasing the interests for foreign direct investments in general.

3. The urban plans, especially for villages must to be managed and controlled together with the development of the territories.

4. The creation of an institutional and legal framework, and a strategy in line with economic, social and environmental factors.

5. A better management of airports, including the networks of agencies on accommodation of foreign visitors and the creation of security and safe traveling.

6. The protection and conservation of natural resources.

7. The new tendencies of construction must preserve the traditional architecture and typical materials.

8. The investment in small and medium entrepreneurship should suit the tastes and demands of periodical tourists.

9. In less visited areas, it should be given more opportunities especially women to get involved in the tourism industry.

10. Establishing financial policies for providing soft loans for the opening of hotels and enterprises of services, vegetables, greenhouses etc.

11. To determine some of the most attractive areas, places to attract visitors such as Children's attractions, events, etc. to entertain visitors.

12. The protecting of the environment is important to determine a plan and immediate measures to protect the environment.

13. The formation of the leading groups of tourists, who know the terrain, also young people that have knowledge of foreign languages, specialists of first aid and medical services, historians and cicerones will high communicative abilities etc.

14. There must be also improved conditions on tourists' services, which may be associated with educational courses on traditional cuisine and nutrition. 


\section{References}

1. Prof.Dr.Ilia Kristo, 'Biznesi Ndërkombëtar', Tirana, Albania, 2002

2. Prof.Dr.Vjollca Bakiu, 'Menaxhimi i Turizmit', Tirana, Albania, 2006

3. Akademik Mark Krasniqi, ''Rugova', Monographs etnografike, Pristina, Kosovo, 1987

4. Dr.Klodiana Gorica, Ma.Fioralba Vela, 'Strategjia e Turizmit'” (politika, projekte, plane), Tirana, Albania, 2007

5. GUNN TOURISM PLANNING, USA, 1993

6. HEALTH, WALL. 'MARKETING TOURISM DESTINACION', USA, 1992

7. Miladinovski, Sofronija. "SI TA KUPTOJMË PROMOVIMIN? Instituti për Studime i Shkencave Organizative-Aplikative "Pjetër Budi"-Pristina (2010): 20.

8. Beqiri, Edmond. "INFORMATIKË BIZNESI ME BIZNES ELEKTRONIK", Prishtina, Kosovo, 2013

9. Rugova Relax (2013) http://www.rugovarelax.com/en/index.php

10. World Tourism Organization UNWTO /http://media.unwto.org/en/content/understandingtourism-basic-glossary 